\title{
RECONVERSIÓN PRODUCTIVA DEL TABACO EN MÉXICO, UN ACERCAMIENTO DESDE LA ETNOGRAFÍA INSTITUCIONAL ${ }^{1}$
}

\author{
Dagoberto de Dios Hernández² \\ Jesús Antonio Madera Pacheco ${ }^{3}$ \\ Leonardo Xavier Da Silva ${ }^{4}$
}

\begin{abstract}
RESUMEN
Nayarit concentra aproximadamente $90 \%$ de la superficie cultivada de tabaco en México, parte importante de su economía e identidad sociocultural se anclan al tabaco. A más de una década de ratificado el Convenio Marco para el Control del Tabaco, y su traducción en el programa de Reconversión Productiva del Tabaco (RPT) para el cumplimiento de los artículos No. 17 y No. 18, los rendimientos productivos se mantienen sin cambios y existe una falta de información de las familias en torno a la RPT. El objetivo de este artículo es analizar la situación actual del Programa de RPT y las interfaces entre familias tabacaleras, organizaciones de representación, funcionarios gubernamentales y otros actores en torno a la RPT. Con la etnografía institucional como referencial analítico y metodológico, el artículo da cuenta que dicha intervención gubernamental es compleja y con visiones contradictorias entre sus actores institucionales y sociales. Las acciones emprendidas por el Estado han dificultado y obstaculizado el proceso de RPT, porque los recursos de apoyo para la reconversión de cultivos son objeto de control político evitando que lleguen a las familias tabacaleras en Nayarit.
\end{abstract}

PALABRAS CLAVE: Etnografía institucional, CMCT, políticas públicas, reconversión, tabaco

\section{RECONVERSÃO PRODUTIVA DO TABACO NO MÉXICO, UMA APROXIMAÇÃO DESDE A ETNOGRAFIA INSTITUCIONAL}

\begin{abstract}
RESUMO
Aproximadamente $90 \%$ da superfície cultivada de tabaco no México concentram-se no estado de Nayarit, dinamizando parte importante da sua economia e uma identidade sociocultural atrelada ao tabaco. Após mais de uma década da ratificação

\footnotetext{
1 Este trabajo forma parte del proyecto de Ciencia Básica: A1-S-17116 "Desafíos de la Reconversión Productiva y sus contribuciones para la construcción de seguridad alimentaria en municipios productores de tabaco en Nayarit", financiado por el Consejo Nacional de Ciencia y Tecnología (CONACYT) de México.

2 Ingeniero en Desarrollo e Innovación Empresarial (UTC). Maestro en Desarrollo Económico Local (UAN). Doctorando en Desarrollo Rural (UFRGS). Asistente de investigación del cuerpo académico Actores Sociales y Desarrollo Comunitario, de la Universidad Autónoma de Nayarit (UAN), México. E-mail: dagobertodediosh@gmail.com

${ }^{3}$ Licenciado en Economía (UAN). Maestro en Desarrollo Regional (COLEF). Doctor en Agroecología, Sociología y Desarrollo Rural Sostenible (UCO). Profesor-investigador en el Área de Ciencias Sociales y Humanidades de la Universidad Autónoma de Nayarit (UAN), México. E-mail: jmadera@uan.edu.mx

${ }^{4}$ Graduado en Ciencias Económicas (PUCRS). Maestro en Economía Rural (UFRGS). Doctor en Economía (UFRGS). Profesor del Departamento de Economía y del programa de posgrado en Desarrollo Rural (PGDR) de la Universidad Federal de Rio Grande del Sur (UFRGS). E-mail: leonardo.xavier@ufrgs.br
} 
da Convenção-Quadro para o Controle do Tabaco (CQCT), e da sua tradução no programa de Reconversão Produtiva do Tabaco (RPT) para dar cumprimento os artigos 17 e 18, os rendimentos produtivos se mantêm sem câmbios, além da existente falta de informação e desconhecimento das famílias em torno à RPT. O objetivo principal é analisar e identificar a situação atual do Programa de RPT e as interfaces entre as famílias fumicultoras, suas organizações, funcionários governamentais e outros atores. Apoiando-se da etnografia institucional como referencial analítico e metodológico, o artigo da conta que esta intervenção governamental é complexa e com visões contraditórias entre seus atores. Inclusive, as ações empreendidas pelo Estado, longe de facilitar o processo têm-lo dificultado e obstaculizado, porque os recursos de apoio são objeto de controle político evitando que cheguem até as famílias fumicultoras de Nayarit.

Palavras-chave: Etnografia institucional, CQCT, políticas públicas, reconversão, tabaco.

\section{INTRODUCCIÓN}

El Programa de Reconversión Productiva del Tabaco (RPT) en Nayarit forma parte de los compromisos a los cuales México se suscribió con la ratificación en 2004 del Convenio Marco para el Control del tabaco (CMCT), en particular con los artículos No. 17 y No. 18, que tenían como fin promover entre las familias productoras un proceso de transición hacia cultivos como granos básicos, frutales y hortalizas; así como el cuidado del medio ambiente y salud de las personas. La Secretaría de Agricultura, Ganadería, Desarrollo Rural, Pesca y Alimentación (Sagarpa), fue la responsable de la elaboración de programas y proyectos para la operacionalización de esa intervención gubernamental, valiéndose de la estructura institucional creada a partir de la Ley de Desarrollo Rural Sustentable implantada en la administración de Vicente Fox Quezada (2000-2006), donde se contemplaba la Reconversión Productiva Sustentable dentro del Programa Nacional Integral de Reconversión Productiva. Bajo ese marco, fueron convocadas otras organizaciones como el Instituto Nacional de Investigaciones Forestales, Agrícolas y Pecuarias (Inifap), y la Secretaría de Desarrollo Rural y Medio Ambiente (Sederma) de Nayarit, para ser parte del conjunto de actores y agencias de Estado que instrumentalizaran el Programa de Reconversión Productiva del tabaco y sus recursos en Nayarit, México.

Nayarit posee un papel importante en la producción de tabaco a nivel nacional, pues se trata del principal estado productor con aproximadamente $90 \%$ de la superficie cultivada en México. A pesar de que los rendimientos productivos de este cultivo han disminuido, continúa teniendo una importancia fundamental en términos sociales y económicos para las aproximadamente tres mil familias que aun continúan en la actividad. En municipios como Santiago Ixcuintla, la producción de tabaco deja una derrama económica importante que se traduce en fuentes de empleo y ganancias finales, así como beneficios sociales por el acceso a la seguridad social y a una pensión rural, a las familias tabacaleras.

A más de una década de ratificado el CMCT y de su traducción en el Programa de RPT, se ha podido documentar en Nayarit una serie de contradicciones, vacíos de información e inconsistencias en su real aplicación y en los resultados que inicialmente habían sido establecidos (DE DIOS, 2014; MADERA; DE DIOS, 2017). Por otro lado, las relaciones entre el Estado, funcionarios 
gubernamentales, familias tabacaleras y otros actores son confusas, puesto que se percibe que dicha intervención ha generado mayores dudas y cuestionamientos, que resolver propiamente los compromisos de la reconversión de cultivos por tabaco. Habiendo pasado más de diez años, se convierte en objetivo principal de este trabajo, analizar e identificar la situación actual del Programa de RPT como una intervención gubernamental y las interfaces entre las familias tabacaleras, organizaciones de representación, funcionarios gubernamentales y otros actores en torno a este programa.

Con apoyo de la etnografía institucional como referencial analítico y metodológico, ha sido posible documentar que el Programa de RPT en Nayarit es una intervención gubernamental bastante compleja, con variedad de discursos y marcadas contradicciones entre los diversos actores y las dependencias del Estado, pero sin resultados o avances que hasta el momento evidencien un real apoyo a las familias productoras en la transición productiva del tabaco hacia cultivos económica y socialmente más viables y rentables.

La etnografía institucional ha permitido identificar una existente desconexión de las funciones legales y reales de las Instituciones gubernamentales, que en el papel son unas y en campo otras. Esto, porque en el largo plazo los recursos económicos de apoyo a los cuales se ha podido acceder, terminan siendo utilizados por parte de agricultores que, si bien requieren de la intervención del gobierno, no se trata en todo caso de productores de tabaco. Es decir, dichos recursos están destinándose a cultivos que sí están enmarcados como parte de las opciones de reconversión, pero no están siendo las familias tabacaleras sus beneficiarias o destinatarias finales.

Al disgregar el Programa de RPT se ha podido apreciar una serie de contradicciones en diferentes sentidos y niveles. Éstas van desde las instancias oficiales como SAGARPA, políticos y gobernantes, hasta productores de tabaco y los líderes de sus organizaciones, quienes se confrontan en sus discursos en un aparente ring virtual de debates en torno de los supuestos recursos de apoyo. Si bien se señalan una variedad de montos de apoyo, dinero invertido y programas o componentes desde donde se han gestionado, éstos simplemente no coinciden, pues cada fuente de información oficial consultada presenta una serie de datos diferentes o que no están alineados conforme a lo que se dice, respecto de lo que se hace.

Así, el presente trabajo está compuesto, además de esta introducción, por una breve descripción y caracterización de las familias tabacaleras en torno a la producción de tabaco en Nayarit. Enseguida, presentamos una propuesta analíticometodológica de la etnografía institucional como referencial para el abordaje del problema. Después, los resultados son discutidos en torno a la situación actual del Programa de RPT y de las interfaces entre los diversos actores vinculados a la producción de tabaco en Nayarit. Finalmente, se encierra el trabajo con algunas reflexiones finales y las posibles vertientes nuevas de investigación. 


\section{LAS FAMILIAS PRODUCTORAS DE TABACO EN NAYARIT, MÉXICO. ALGUNOS DATOS PARA SU COMPRENSIÓN}

En México, la producción de tabaco se localiza principalmente en Nayarit ${ }^{5}$, donde se cultivan las variedades Virginia y Burley. Este estado respondió en el ciclo 2017-2018 por aproximadamente $90 \%$ de la superficie cultivada con 5,410 hectáreas de las 6,070 registradas a nivel nacional y una producción total de 13,470 toneladas equivalentes al $92.31 \%$ del total mexicano. Actualmente, son aproximadamente tres mil familias tabacaleras quienes, con un promedio de dos hectáreas, producen 2.405 toneladas/ha (SIAP, 2019).

Si bien la figura de "productor" recae en una persona, la producción de tabaco se da en un contexto familiar, con una distribución del trabajo por sexo y edad donde al final, todos los integrantes del núcleo familiar se ven involucrados, de ahí el término de "familias del tabaco" (MADERA, 2000; CAYEROS, 2007) del que en este trabajo nos hacemos eco. En algunos casos y especialmente en temporada de cosecha, se contrata trabajadores temporales. Estas familias tabacaleras, producen además alimentos para autoconsumo entre los que se destacan principalmente el frijol, maíz, chile, nopal, algunas hortalizas y frutales. En los últimos diez años (2009-2018) la producción de tabaco se ha recuperado y estabilizado en torno a cinco mil hectáreas plantadas.

Tabla1 - Área total cultivada con tabaco en México y los aportes absolutos y porcentuales de Nayarit al total nacional (2009 a 2018 - miles de hectáreas-)

\begin{tabular}{|c|c|c|c|c|}
\hline \multirow{2}{*}{ Año } & \multicolumn{2}{|c|}{ México } & \multicolumn{2}{c|}{ Nayarit } \\
\cline { 2 - 5 } & Total & $\%$ & \multicolumn{1}{c|}{ Total } & $\%$ \\
\hline 2018 & 6.070 & 100 & 5.410 & 89.12 \\
\hline 2017 & 7.462 & 100 & 6.207 & 83.18 \\
\hline 2016 & 7.183 & 100 & 5.930 & 82.55 \\
\hline 2015 & 7.939 & 100 & 6.411 & 80.75 \\
\hline 2014 & 8.004 & 100 & 6.773 & 84.62 \\
\hline 2013 & 7.428 & 100 & 6.122 & 82.41 \\
\hline 2012 & 6.959 & 100 & 5.688 & 81.73 \\
\hline 2011 & 4.524 & 100 & 3.187 & 70.44 \\
\hline 2010 & 4.459 & 100 & 3.085 & 69.18 \\
\hline 2009 & 4.328 & 100 & 3.066 & 70.84 \\
\hline
\end{tabular}

Fuente: elaboración propia con datos de SIAP (2019).

A pesar de que la producción mexicana de tabaco no ocupa los primeros puestos del ranking mundial, su importancia es trascendental para un estado como

${ }^{5}$ El resto de la producción de tabaco en México se localiza en los estados de Veracruz, Chiapas, Guerrero y Tabasco que contabilizaron conjuntamente 660 hectáreas plantadas y 1,122 toneladas producidas, o sea, $10.87 \%$ y $7.68 \%$ respectivamente (SIAP, 2019 ). 
Nayarit y sus municipios, donde las familias tabacaleras están vinculadas a esta actividad, por su importancia social, económica y cultural que se adecua a las pequeñas propiedades; es el caso, por ejemplo, de Santiago Ixcuintla ${ }^{6}$, el municipio productor más importante a nivel nacional, donde, según datos del SIAP (2019), se cultivaron para el ciclo 2017-2018 una superficie de 3,865 hectáreas que resultaron en una producción de 9,778 toneladas, con un rendimiento promedio de 2.530 toneladas por hectárea.

Además de ello (la información más reciente disponible), los rendimientos económico-productivos del tabaco para el ciclo 2011-2012 en Santiago Ixcuintla se aproximaron a una producción de $6,133.50$ toneladas con un rendimiento promedio por hectárea de $2.9^{7}$ toneladas, generando un valor total de la producción en moneda brasileña de $\mathrm{R} \$ 28.687 .993,77$ (77.72\%) de los $\mathrm{R} \$ 36.908 .530,00$ obtenidos como derrama económica total por el cultivo de tabaco a nivel estatal ${ }^{8}$.

\section{METODOLOGÍA}

El contexto rural donde se desarrolla principalmente la actividad tabacalera del estado de Nayarit no ha quedado fuera del control político-institucional operado históricamente desde el Estado mexicano. Al igual que el amplio sector rural campesino en México, la producción de tabaco ha venido padeciendo la falta de rectoría gubernamental para potencializar las capacidades productivas locales, creando a lo largo del territorio nacional diversos problemas producto de una deficiente calidad en la intervención estatal, de la corrupción generalizada, del clientelismo y de una manipulación política (MACKINLAY, 2008, p. 169; apud FLETES, ET. AL., 2014).

La etnografía institucional, una herramienta analítico-metodológica, es "un estudio etnográfico de las operaciones reales de una Institución, que permite tener acceso a la lógica interna de sus instituciones específicas para dar cuenta de sus cambios y continuidades" (FOX, 2005, p. 87; apud HEVIA, 2011, p. 337); permite incorporar en una investigación una visión que desmenuza por completo la operación in situ de un programa gubernamental (TORRES ET. AL, 2015). Sin embargo, su mayor relevancia descansa en "enfatizar la función de los actores locales en su relación con los actores institucionales, considerando no solo aspectos de gestión pública, sino también una lectura sociopolítica y antropológica de la gobernanza en un contexto local" (TORRES, ET. AL, 2015, p. 53).

De acuerdo con Vizcarra y Farfán (2011), las investigaciones apoyadas en estudios de etnografía institucional han desarrollado una propuesta metodológica cualitativa que permite abordar un problema desde dos perspectivas. Por un lado, conocer cómo se realiza la construcción de un problema por parte del gobierno y como éste elabora una justificación de intervención con el pretexto de resolver dicho problema, de modo que nos ayuda a discernir si los problemas realmente corresponden o no a los de la población afectada. Por el otro, esta metodología permite indagar si en realidad una intervención gubernamental se trata de estrategias de dominación más amplias que tienen por fin controlar la vida de las poblaciones afectadas, de manera que estos grupos sociales no puedan atentar

\footnotetext{
6 Para el ciclo 2017-2018, dicho municipio aportó a la producción nacional el $63.67 \%$ de la superficie cultivada y $67 \%$ del volumen total producido (SIAP, 2019).

7 Para el mismo año se tuvo un rendimiento promedio por hectárea a nivel estatal de 2.4 (ARIC, 2013), mientras que a nivel nacional fue de 2.05 (SIAP, 2012).

${ }^{8}$ En pesos mexicanos, el "Valor Total da Produção (VTP)" sería de 171 millones de los 220 millones totales. Según la calculadora de tipos de cambio y de divisas del Banco de México, la conversión resultaría en las cifras presentadas en reales $(\mathrm{R} \$)$. Calculadora disponible en: <http://www.xe.com/es/>.
} 
contra los intereses que sostienen las estructuras del poder (VIZCARRA; FARFÁN, 2011).

Frente a la realidad actual de la producción de tabaco en Nayarit y el status que guarda el Programa de RPT, el uso de la etnografía institucional como referencial analítico-metodológico nos permitirá, de acuerdo con Torres, et. al. (2015) centrar y focalizar un análisis micro a escala territorial, que devele el papel de los actores con la política y su operación en el espacio local. Así, la presente investigación se apoya en la propuesta metodológica enunciada por la etnografía institucional (VIZCARRA; FARFÁN, 2012; TORRES, ET AL., 2015) como una herramienta para el análisis del programa de RPT en México, que nos permita adentrarnos en la lógica de funcionamiento de dicha intervención gubernamental, de las relaciones verticales y horizontales de sus agentes y beneficiarios, así como de las diferentes partes que la componen.

Las principales fuentes de información consultadas están organizadas en torno a tres grupos. El primero de ellos se refiere a los documentos e información oficial generados desde las instituciones del Estado mexicano, sobre todo aquellas relacionadas con SAGARPA y SEDERMA, tanto estudios en físico, como aquella información disponible en sus sitios de internet. El segundo grupo comprende un acervo hemerográfico que ha sido construido desde 2012 a la fecha con artículos y notas de periódico, que para este trabajo fueron consultados solamente para el periodo 2012-2017, en torno a temas relacionados con la RPT en Nayarit. El tercer grupo comprende una serie de entrevistas realizadas a familias tabacaleras y a otros actores relacionados con la producción del tabaco en Nayarit en 2014.

Triangular las fuentes de información descritas nos permitió realizar una revisión de la trayectoria histórica de la RPT con sus cambios y continuidades, en torno a cómo se ha venido construyendo un problema desde el Estado para intervenir en la realidad tabacalera; así como identificar las acciones y recursos destinados, quiénes y cómo han venido manejándolos; además de las interfaces entre los diversos actores, entre ellos las familias tabacaleras quienes viven en campo las contradicciones y la desinformación en torno al CMCT y a la RPT.

\section{RESULTADOS Y DISCUSIÓN}

\subsection{EL CONVENIO MARCO PARA EL CONTROL DEL TABACO Y EL PROGRAMA DE RECONVERSIÓN PRODUCTIVA DEL TABACO EN MÉXICO}

EI CMCT es un acuerdo mundial de salud que pretende dar respuesta a la epidemia global del tabaquismo. Se convirtió en el primer instrumento jurídico internacional de carácter vinculante que demanda de los llamados Estados Parte el establecimiento de políticas para controlar la oferta y demanda de productos de tabaco por un tema de salud pública (GÁMEZ ET AL., 2013), buscando reducir la mortalidad atribuible al tabaquismo. Para la Organización Mundial de la Salud (OMS), principal promotora del CMCT, el cultivo de tabaco "agrava en particular los trastornos sociales y la pobreza, originando un régimen de esclavitud laboral y trabajo infantil; además de las repercusiones en el medio ambiente y la salud de las personas"9 (OMS, 2014, p. 5).

\footnotetext{
${ }^{9}$ De acuerdo con la OMS, el objetivo del CMCT es "proteger a las generaciones presentes y futuras de las devastadoras consecuencias sanitarias, sociales, ambientales y económicas generadas por el consumo y por la exposición al humo de tabaco, proporcionando una referencia para las medidas de control del tabaco, a ser implementadas por las Partes en los niveles nacional, regional e internacional, a fin de reducir de manera continua y substancial la prevalencia del consumo y la exposición al humo de tabaco" (OMS, 2014, p. 4).
} 
El CMCT se adoptó en la ciudad de Ginebra, Suiza, el 21 de mayo de 2003 (DOF, 2005) en el marco de la 56 asamblea Mundial de Salud (ASM), como parte de los trabajos realizados por la propia OMS, aunque las primeras discusiones en torno del tabaquismo se remontan a la década de 1960, y continúan con mayor fuerza durante 1970 a 1980 (MENGEL, 2011).

Posterior a su adopción, México se convirtió en el primer país del continente americano en ratificar dicho Convenio (REGALADO; RODRÍGUEZ, 2008), en un proceso rápido y controversial ${ }^{10}$, dejando fuera de los debates y negociaciones a los productores tabacaleros nayaritas representados a través de la Asociación Rural de Interés Colectivo (ARIC) del tabaco. Resultado de su adhesión y ratificación, el gobierno mexicano se comprometió a cumplir con las obligaciones contenidas en el Convenio. Concerniente a las familias productoras de tabaco que tienen como medio de vida este cultivo, se destacaron los artículos No. 17: promover alternativas económicamente viables para los trabajadores, los cultivadores y, eventualmente los pequeños vendedores de tabaco; y No. 18: protección del medio ambiente y la salud de las personas (OMS, 2014, p. 14).

La traducción del CMCT, sobre todo en el tema de políticas públicas para el cumplimiento de los artículos mencionados, quedó sobre la responsabilidad de la Sagarpa, quien se encargaría de crear programas y proyectos para integrar una serie de políticas en apoyo a la diversificación de las regiones productoras y preparar a los agricultores ante una posible retracción de la demanda mundial de tabaco (SAGARPA, 2008). Para llevar a cabo esa encomienda, dicha Secretaría se basó en la estructura institucional creada con el Programa Nacional Integral de Reconversión Productiva y el componente de Reconversión Productiva Sustentable, ambos derivados de la Ley de Desarrollo Rural Sustentable (LDRS) ${ }^{11}$. A través de esta estructura institucional previa es que fue construido el Programa de RPT (SAGARPA, 2008).

Para establecer diferencias que nos permitan no causar más confusiones de las ya existentes, tanto en la documentación oficial, como en el contexto tabacalero nayarita, llamaremos para fines de este trabajo Programa de Reconversión Productiva del Tabaco a todo aquello relacionado con acciones de política pública provenientes de las Instituciones y actores del Estado; reconversión del tabaco al proceso de cambio o transición productiva de éste a otros cultivos, y; Reconversión Productiva al componente mediante el cual específicamente se asignan o debieran haberse asignado recursos económicos de apoyo.

Como una vertiente de la LDRS, el Programa Nacional Integral de Reconversión Productiva facilitó la traducción de políticas provenientes del CMCT, en concreto, aquellas referentes a las obligaciones para con las familias dedicadas al cultivo de tabaco en México. Al ser una política de carácter sectorial destinada al ámbito agrícola, la Reconversión Productiva promovía la transformación integral de las actividades productivas y de su entorno, proponiendo para ello los cuatro llamados tipos de reconversión: i) cambios tecnológicos, ii) conversión de cultivos, iii) reconversión productiva y, iv) recuperación de zonas degradadas (SAGARPA, 2004). De acuerdo con el documento Institucional, la "reconversión productiva" era descrita como el:

\footnotetext{
10 Una de las controversias, es la rapidez del proceso de ratificación llevado a cabo en aproximadamente ocho meses. El tratado fue firmado el 12 de agosto de 2003, para después ser remitido a la Cámara de Senadores quien aprobó el documento el 14 de abril y enseguida pasó al Ejecutivo Federal quien lo ratificó finalmente el 17 de mayo para depositarlo en la Organización de las Naciones Unidas el 28 de mayo de 2004 (DOF, 2005).

${ }^{11}$ Política del sexenio gubernamental del presidente Vicente Fox Quezada (2000-2006).
} 
Cambio de la actividad forestal, agrícola o pecuaria, buscando aprovechar la aptitud potencial del área o sitio con un uso óptimo del suelo y reducir la siniestralidad, para alcanzar una producción capaz de competir exitosamente en la defensa del mercado local y de lograr una incursión eficiente en los mercados externos (SAGARPA, 2004, p. 6).

Sin embargo, una de las primeras confusiones se encuentra aquí, puesto que la conversión de cultivos parece estar más próxima del contenido normativo que implica el cumplimiento de los compromisos en torno del artículo No. 17. Conforme Sagarpa, dicha conversión comprende la "introducción o establecimiento de un cultivo o especies alternativas por otro que tiene mejor adaptación agroecológica y con mayor competitividad" (SAGARPA, 2004, p. 6). A pesar de ello, para determinar cuáles serían las llamadas alternativas económicamente viables a sustituir el cultivo de tabaco (Articulo No. 17), Sagarpa encomendó al Inifap la elaboración de un Estudio de Potencial Productivo que contendría la estrategia guía para llevar a cabo la implementación de tal proceso. A groso modo y mediante un análisis costobeneficio, INIFAP propuso que la reconversión del tabaco podría realizarse en un periodo de tres años (2008 a 2010) a través de cultivos clasificados en tres categorías: a) granos básicos: sorgo, arroz, maíz y frijol; b) frutales: papaya, cítricos, mango y plátano, principalmente; y, c) hortalizas: tomate, chile verde y otras hortalizas.

Adicionalmente, Inifap propuso como posible para ese periodo "la reconversión productiva de 6,000 hectáreas del cultivo del tabaco, hacia otros que consideraba con un alto potencial productivo, con buena rentabilidad y demanda, tanto en los mercados regionales, nacional y/o de exportación, que permitan a los productores obtener ingresos similares o superiores a los obtenidos con el tabaco" (SAGARPA, 2008, p. 25). Sin embargo, estudios realizados por De Dios (2014) y Madera y De Dios (2017), dejan ver la inexistencia de una reconversión de esas 6,000 hectáreas, ni de la presencia de otros cultivos en substitución del tabaco. Mucho menos, en dicho Estudio de Potencial Productivo fueron considerados los supuestos criterios de tipo agroecológico, temporalidad y sustentabilidad de los cultivos propuestos.

Por otro lado, para la asignación presupuestal de los recursos de apoyo, el gobierno se ayudó de un componente de Reconversión Productiva que ya existía. Éste fue creado inicialmente e instrumentado para dar atención al cultivo de frijol en el ciclo 2007-2008 en los estados de Durango, San Luis Potosí y Zacatecas ${ }^{12}$. Sin embargo, a pesar de que el componente se fue expandiendo tanto a cultivos y estados beneficiados, en el caso del tabaco, su turno llegó hasta 2012 (SAGARPA, 2012). Un documento de Sagarpa (2012) demuestra, por primera vez desde la ratificación del CMCT, la existencia oficial de recursos de apoyo comprometidos para la Reconversión del tabaco, contemplándose de manera explícita como "apoyos a la Reconversión de tabaco a granos básicos en el estado de Nayarit". Esto genera algunas controversias y dudas, puesto que según desde el año 2008 en el marco de promulgación de la Ley General para el Control del Tabaco (LGCT), líderes y productores tabacaleros conscientes de que la LGCT era una situación irreversible que terminaría por agravar aún más la producción tabacalera, habrían conseguido gestionar ante gobierno apoyos que los orientarían en el cambio a nuevos cultivos

\footnotetext{
${ }^{12}$ Esos estados fueron afectados, en ese periodo por una fuerte sequia, lo cual justificó por parte del Estado que "requerían de un mayor ordenamiento y control sobre el mercado, al mismo tiempo que se pudiera generar una mejor remuneración final para los productores” (SAGARPA, 2012).
} 
(NOTIMEX, 2008). Sin embargo, tal parece que éstos se tardaron cuatro años en llegar.

A pesar de que se tiene conocimiento -según versiones de diferentes periódicos de circulación local y nacional- que los primeros recursos económicos de apoyo a la Reconversión del tabaco llegaron a partir de 2009, no fue sino hasta 2011 que según lo documentado por diferentes actores políticos y otros medios de comunicación, es que se crea el llamado "Fondo de Reconversión Productiva en plantaciones de tabaco para cigarrillos", a través del cual en el presupuesto de egresos de la federación se comenzarían a etiquetar recursos para ayudar a las familias productoras en la promoción e incentivo hacía los cultivos alternativos (MADERA; DE DIOS, 2017). Es decir, existe un lapso de cuatro años en el cual el gobierno finalmente, después de ocho años de ratificar el CMCT, hace llegar los primeros recursos a las familias productoras de tabaco.

Sin embargo, poco o nada se sabe de esos "apoyos a la Reconversión de tabaco a granos básicos en el estado de Nayarit" o del Fondo de Reconversión Productiva en plantaciones de tabaco para cigarrillos. Los recursos que han llegado a Nayarit para la substitución del tabaco, cuando así ha sido, vienen de lo que algunos actores continuamente han mencionado como diferentes partidas presupuestales, pero no del Componente o Fondo ya mencionado. Aunque, manifestado así en declaraciones de políticos y líderes campesinos, la asignación de recursos ha sido producto de movilizaciones y manifestaciones de productores para exigir los tan anunciados y necesarios apoyos. Por otro lado, hay actores que aseguran se ha vuelto un proceso excesivamente burocrático la gestión de recursos, lo cual ha impedido el acceso a los mismos.

El escenario actual que parece se ha construido desde el CMCT para justificar la intervención en la producción tabacalera nayarita, presenta características de una estrategia de biopolítica. Las circunstancias actuales apuntan a que los agentes gubernamentales con poder se han estado aprovechando para retener 0 extraer todos los beneficios posibles que debían llegar a las familias tabacaleras a quienes constituyeron como la materia prima y el substrato (FOUCAULT, 2008; apud VIZCARRA; FARFÁN, 2012), para justificar la elaboración del Programa de RPT.

Por otro lado, es posible prever que la dificultad de articulación entre las instituciones y agentes del Estado para con sus beneficiarios, no será posible encontrarla en el ámbito del diseño, sino en la implementación de la política (ARELLANO; CABRERO; DEL CASTILLO, 2007; apud HEVIA, 2011). En el caso del Programa de RPT, si se trae a consideración dicho argumento, podría entenderse que a pesar de encontrarse bien fundamentado en el papel a través de la Ley de Desarrollo Rural Sustentable, las dificultades para su implementación se encuentran en la realidad, pero habría que ponderar cuan responsable es el entorno, porque podrían ser propiamente las mismas Instituciones y agentes gubernamentales quienes la manipulan según sus lógicas e intereses. En ese sentido, cobra bastante relevancia otro argumento venido desde el enfoque organizacional, según el cual se define al gobierno "como una red de organizaciones con pretensiones que nunca alcanzaran una actuación homogénea, lógica y continuada, lo que elimina por tanto la idea de que el Estado sería un ente monolítico y homogéneo" (MIGDAL, 2001; apud HEVIA, 2011), de manera que las acciones, recursos y demás compromisos suscritos en el documento oficial, no garantiza la convergencia de esfuerzos y actividades de las partes del Estado como un todo para su óptimo funcionamiento, pues cada una entiende y atiende según sus intereses. 


\subsection{LA ACTUALIDAD DEL PROGRAMA DE RECONVERSIÓN PRODUCTIVA DEL TABACO EN EL ESTADO DE NAYARIT}

La situación actual del Programa de RPT en Nayarit es la de un proceso complejo de entender, confuso y contradictorio, que parece no tener éxito, ni resultados. Además de las controversias y contradicciones de sus diferentes actores, parece existir una falta de coordinación y de trabajo conjunto entre las dependencias y organizaciones responsables de su implementación, donde todo indica que la realidad de esta intervención planeada obedece a una lógica de desinterés o de acciones meramente paliativas, como un nuevo embate del Estado hacia el sector rural. Todo se remite a la naturaleza dual de sus organizaciones; unas en el papel, otras en la realidad.

Razón aparte es la complejidad de lo que se entiende por RPT. Si bien, por parte de algunos actores políticos, dependencias de Estado y líderes campesinos se refieren a ella de manera indistinta como una política agrícola o como un programa gubernamental, ni en el papel, ni en la práctica terminan por diferenciarse. La Reconversión Productiva, formaba parte del Programa Nacional Integral de Reconversión Productiva que ayudaría en el cumplimiento de los objetivos, metas y/o acciones de la LDRS, sin embargo, es llamada indistintamente bajo nombres como "programa", "componente" o "vertiente", sin ningún cuidado de las distinciones cuando se referían a ella. La pregunta entonces, ¿Cómo se llega al establecimiento y nombramiento de la Reconversión del tabaco?

La reconversión del tabaco es oficialmente llamada así a partir de 2012 en que se inserta por primera vez como una vertiente de apoyo en el "Componente Reconversión Productiva" del "Programa de Sustentabilidad de los Recursos Naturales", de la Dirección General de Fomento a la Agricultura de la Sagarpa. Según el documento Memoria Documental del Componente Reconversión Productiva 2006-2012, la denominada, vertiente de "Apoyo a la Reconversión de tabaco a granos básicos en el Estado de Nayarit", habría sido por primera y parece que única vez, susceptible de una superficie de apoyo de 13.7 mil hectáreas $(2.10 \%)$, de las 651 mil programadas y apoyadas a nivel nacional como parte del componente en cuestión. Además de otras vertientes ya apoyadas en Nayarit, como lo fueron Pro-oleaginosas con los cultivos de soja y canola, así como maíz de alto y medio rendimiento en diferentes ciclos agrícolas; la del tabaco, en este caso, fue apoyada durante el ciclo primavera-verano 2012 con la dotación de paquetes tecnológicos para la reconversión a granos básicos como: arroz, frijol, maíz y sorgo.

Se menciona en dicho documento que los apoyos del componente RPT estarían destinados básicamente a atender lo que serían cuatro áreas prioritarias con una distribución porcentual de recursos de la siguiente manera: a) recuperación de la vocación del suelo (32\%), b) ordenamiento del mercado (32\%), c) incremento de la producción interna (36\%), y d) siniestros (no recibió recurso). Sin embargo, en dicho documento no se hace mención explícita de la cantidad de recursos económicos que comprendían el componente de Reconversión.

La tabla 2 muestra un concentrado de los recursos que, a nivel federal y estatal, al menos en el papel y con una diversidad de nombres se han destinado al Programa de Reconversión Productiva del tabaco. La primera parte (fila 1), a través del análisis hemerográfico retoma las declaraciones de diferentes actores en relación al tema, rescatando a partir de sus señalamientos los recursos y los programas desde los cuales habrían llegado éstos para ser dispersados a los productores. En cambio, la segunda parte (filas 2 y 3), concentra información de carácter oficial disponible en las páginas de internet de la delegación de Sagarpa en 
Nayarit, de SEDERMA local y del Presupuesto de Egresos contenido en el Diario Oficial de la Federación (DOF) de Nayarit. En estos documentos, también se hace mención y referencia a los recursos destinados a partir de los diferentes programas, componentes o vertientes que tenían como objetivo el Programa de Reconversión.

Tabla 2 - Recursos canalizados por diferentes programas a través de la Reconversión Productiva del tabaco

\begin{tabular}{|c|c|c|c|c|c|}
\hline $\begin{array}{l}\text { Concentración } \\
\text { de recursos } \\
\text { seqún nivel }\end{array}$ & Período & $\begin{array}{c}\text { Dependencia } \\
\text { s/ } \\
\text { programas }\end{array}$ & $\begin{array}{c}\text { Recursos } \\
\text { (millones de } \\
\text { pesos - MDP) }\end{array}$ & $\begin{array}{l}\text { Rubros de } \\
\text { aplicación }\end{array}$ & Fuente \\
\hline \multirow{6}{*}{$\begin{array}{l}\text { Federal y estatal } \\
\text { (Concentrado de } \\
\text { información a } \\
\text { partir de } \\
\text { artículos de } \\
\text { internet y } \\
\text { periódicos } \\
\text { digitales) }\end{array}$} & \multirow{6}{*}{$\begin{array}{l}2009- \\
2014\end{array}$} & $\begin{array}{l}\text { Sagarpa } \\
\text { federal } \quad y \\
\text { estatal }\end{array}$ & $\$ 100 \mathrm{MDP}$ & $\begin{array}{l}\text { Nivelación } \text { de } \\
\text { tierras, insumos } \\
\text { agrícolas } y \\
\text { análisis de suelos }\end{array}$ & \multirow{6}{*}{$\begin{array}{l}\text { Ceballos, } \\
2009 \\
\text { Durán, } 2013 \\
\text { Pérez, } 2010 \\
\text { León, } 2012 \\
\text { Lugo, } 2014\end{array}$} \\
\hline & & Infraestructura & $\begin{array}{r}\$ 30 \text { MDP } \\
\$ 26 \text { (de 400) } \\
\text { MDP }\end{array}$ & $\begin{array}{l}\text { Drenaje parcelario } \\
\text { y adquisición de } \\
\text { una central de } \\
\text { servicios }\end{array}$ & \\
\hline & & Productividad & \$15 MDP & $\begin{array}{l}\text { Reconversión de } \\
\text { cultivos }\end{array}$ & \\
\hline & & $\begin{array}{l}\text { Fondo } \\
\text { especial de } \\
\text { Reconversión } \\
\text { Productiva en } \\
\text { las } \\
\text { plantaciones } \\
\text { de tabaco } \\
\text { para cigarrillo }\end{array}$ & $\begin{array}{r}\$ 76 \text { (de 325) } \\
\text { MDP } \\
\$ 26 \text { (de 350) } \\
\text { MDP }\end{array}$ & $\begin{array}{l}\text { Reconversión de } \\
\text { cultivos de } \\
\text { Fondo do de } \\
\text { garantía, tecnificar } \\
\text { riego y bodegas } \\
\text { graneleras }\end{array}$ & \\
\hline & & $\begin{array}{l}\text { Reconversión } \\
\text { y } \\
\text { comercializaci } \\
\text { ón }\end{array}$ & $\begin{array}{l}\text { \$23 MDP } \\
\$ 4.5 \mathrm{MDP}\end{array}$ & $\begin{array}{l}\text { Paquete } \\
\text { tecnológico con } \\
\text { semilla certificado } \\
\text { de arroz y } \\
\text { comercialización }\end{array}$ & \\
\hline & & $\begin{array}{l}\text { Plan de } \\
\text { Reconversión } \\
\text { de cultivos a } \\
\text { maíz amarillo }\end{array}$ & $\$ 30 \mathrm{MDP}$ & $\begin{array}{l}\text { Conversión de } \\
\text { cultivo de tabaco y } \\
\text { caña de azúcar } \\
\text { por maíz amarillo }\end{array}$ & \\
\hline \multirow{3}{*}{$\begin{array}{l}\text { Portal de } \\
\text { internet de } \\
\text { SAGARPA } \\
\text { Federal, } \\
\text { Delegación } \\
\text { Nayarit y } \\
\text { SEDERMA }^{13}\end{array}$} & \multirow{3}{*}{$\begin{array}{l}2008- \\
2015\end{array}$} & $\begin{array}{l}\text { Reconversión } \\
\text { productiva }\end{array}$ & $\$ 29,827,664$ & Sin especificar & \multirow{3}{*}{$\begin{array}{c}\text { Portal de } \\
\text { internet de } \\
\text { SAGARPA } \\
y \\
\text { SEDERMA }\end{array}$} \\
\hline & & $\begin{array}{l}\text { Desarrollo de } \\
\text { capacidades, } \\
\text { innovación } \\
\text { tecnológica y } \\
\text { extensión } \\
\text { rural }\end{array}$ & $\$ 3,137,993$ & Sin especificar & \\
\hline & & $\begin{array}{l}\text { Uso } \\
\text { sustentable de } \\
\text { recursos } \\
\text { naturales para } \\
\text { la producción } \\
\text { primaria }\end{array}$ & $\$ 52,443,354$ & $\begin{array}{l}\text { Paquete } \\
\text { tecnológico para } \\
\text { los cultivos de } \\
\text { maíz, maíz de alto } \\
\text { rendimiento, arroz, } \\
\text { arroz milagro } \\
\text { filipino, brócoli y } \\
\text { limón }{ }^{14}\end{array}$ & \\
\hline
\end{tabular}

\footnotetext{
${ }^{13}$ http://www.sederma.gob.mx/Desarrollo\%20Rural/listado\%20de\%20beneficiarios.html ${ }^{14}$ http://www.sagarpa.gob.mx/Delegaciones/nayarit/Lists/Padrn\%20de\%20Beneficiarios/Attachments/203/List ado\%20Componente\%20Reconversion\%20Productiva\%202010.pdf
} 


\begin{tabular}{|c|c|c|c|c|c|}
\hline & & $\begin{array}{l}\text { Recursos } \\
\text { conveniados } \\
\text { Federación- } \\
\text { Estado }\end{array}$ & $\$ 14,713,714$ & $\begin{array}{l}\text { Paquete } \\
\text { tecnológico cultivo } \\
\text { de maíz, durazno, } \\
\text { pistache, } \\
\text { aguacate, café }{ }^{15}\end{array}$ & \\
\hline & & $\begin{array}{l}\text { Productividad } \\
\text { y } \\
\text { competitividad }\end{array}$ & $\$ 4,133,333$ & Sin especificar ${ }^{16}$ & \\
\hline \multirow{3}{*}{$\begin{array}{l}\text { Presupuesto de } \\
\text { Egresos de la } \\
\text { Federación } \\
\text { (PEF)-Nayarit }{ }^{17}\end{array}$} & \multirow{3}{*}{$\begin{array}{l}2015- \\
2017\end{array}$} & $\begin{array}{l}\text { Presupuesto } \\
\text { sectorial } \\
\text { (Desarrollo } \\
\text { económico) (3 } \\
\text { años) }\end{array}$ & $\begin{array}{r}\$ 1,904,514,05 \\
0\end{array}$ & Sin Especificar & \multirow{3}{*}{$\begin{array}{c}\text { http://www.n } \\
\text { ayarit.gob.m } \\
\text { x/transpare } \\
\text { nciafiscal/ }\end{array}$} \\
\hline & & $\begin{array}{l}\text { Programa } \\
\text { Reconversión } \\
\text { Agropecuaria } \\
18\end{array}$ & $\$ 500,000,000$ & Sin Especificar & \\
\hline & & $\begin{array}{l}\text { Convenio } \\
\text { SAGARPA- } \\
\text { SAGADERP }\end{array}$ & $\$ 96,000,000$ & Sin Especificar & \\
\hline
\end{tabular}

Fuente: elaboración propia.

Una de las primeras declaraciones en relación a los recursos de apoyo para la reconversión del tabaco se realizó en 2012 por el entonces subdelegado agropecuario de la Sagarpa en Nayarit al señalar la existencia de un monto de 4.5 millones de pesos en paquete tecnológico de semilla certificada a ser destinados en la margen derecha del río Santiago para productores que quisieran abandonar la producción de tabaco; la intención era que quienes abandonaran el tabaco ahora cultivaran arroz (LEÓN, 2012). Sin embargo, la única relación de beneficiarios con carácter oficial existente por parte de Sagarpa que podría estar relacionado con estos apoyos, sería la de 2010 llamada "Fideicomiso del Fondo de Fomento Agropecuario en el Estado de Nayarit. Componente Reconversión Productiva". Ahí, se enlistan 16 organizaciones de productores quienes recibieron recursos de apoyo por $\$ 3,907,290$, para adquisición complementaria principalmente de paquetes tecnológicos para maíz de alto rendimiento en municipios como Ahuacatlán, Amatlán de Cañas, Jala, Compostela, San Pedro Lagunillas, Santa María del Oro y Tepic.

A pesar de que se encuentran enlistados también productores del municipio de Santiago Ixcuintla (productor de tabaco más importante en México), éstos no eran tabacaleros, sino agricultores organizados en torno del Consejo de Arroceros del Estado de Nayarit A.C. y del Sistema Producto del Estado de Nayarit A.C., quienes recibieron apoyos para paquetes tecnológicos para el cultivo de arroz por una superficie total de 2,126 hectáreas.

La tabla 3, a través de la revisión de los "Convenios de colaboración SAGARPA-Gobierno del Estado de Nayarit" de 2008 hasta 2016, muestra algunos de los programas en los cuales se han comprometido ambos niveles para hacer llegar recursos económicos al sector agrícola nayarita, destacando aquellos que tienen que ver con la Reconversión Productiva, aunque no totalmente con la del tabaco. Se aprecia que en dichos Convenios ya desde 2008 aparece el componente Reconversión Productiva y con él un monto total superior a siete millones de pesos.

${ }^{15}$ http://www.sagarpa.gob.mx/Delegaciones/nayarit/Lists/Padrn\%20de\%20Beneficiarios/Attachments/166/RE CONVERSION\%20PRODUCTIVA\%20-\%20PRIMERA\%20PUBLICACION.pdf

${ }^{16} \mathrm{http}: / /$ www.sagarpa.gob.mx/Delegaciones/nayarit/Documents/CONVENIO 2011.pdf

${ }_{17} \mathrm{http://www.nayarit.gob.mx/transparenciafiscal/des/3} \mathrm{marco} \mathrm{programatico} \mathrm{presupuestal/presupuesto} \mathrm{egres}$ os/2016/presupuesto principales programas.pdf

${ }_{18}$ En lo que respecta al año 2016 y 2017 , no existe en específico recursos para la Reconversión Productiva.

La cantidad que se presenta en la tabla 1, es referente al año 2015 
Sin embargo, hay otras cosas a destacar a través de la información anterior. La primera es que en 2009 y 2010 no hay información disponible para saber si hubo una continuidad de dicho componente. Sobre todo, llama la atención que anteriormente ya se había señalado que recursos de apoyo fueron entregados en Nayarit para la reconversión del cultivo de maíz de alto rendimiento en municipios del sur y de arroz en Santiago Ixcuintla, pero, no están contemplados en dicho convenio. Un detalle más, similar al anterior, es que tampoco existe información del año 2012 mediante la cual se respalde el argumento presentado en la Memoria documental del Componente Reconversión Productiva 2006-2012, donde se señala que en aquel año fueron destinados recursos para la Reconversión del tabaco a granos básicos. 
Tabla 3 - Aportaciones de recursos a partir de los convenios SAGARPA-Gobierno del estado de Nayarit 2008-2016

\begin{tabular}{|c|c|c|c|c|c|c|c|}
\hline \multirow{3}{*}{ Año } & \multirow{3}{*}{ Criterios } & \multicolumn{6}{|c|}{ Aportaciones en recursos (Millones de pesos) } \\
\hline & & \multicolumn{2}{|c|}{ SAGARPA } & \multicolumn{2}{|c|}{ Gobierno de Nayarit } & \multicolumn{2}{|l|}{ Total } \\
\hline & & $\begin{array}{l}\text { Millones de } \\
\text { pesos }\end{array}$ & $\%$ & $\begin{array}{l}\text { Millones de } \\
\text { pesos }\end{array}$ & $\%$ & $\begin{array}{l}\text { Millones de } \\
\text { pesos }\end{array}$ & $\%$ \\
\hline \multirow{3}{*}{2008} & Total de programas & $\$ 595,940,925$ & 84.2 & $\$ 111,578,900$ & 15.7 & $\$ 707,519,825$ & 100.0 \\
\hline & $\begin{array}{lr}\text { Programa } & \text { de } \\
\text { Atención } & \text { a } \\
\text { Problemas } & \\
\text { Estructurales } & \end{array}$ & $\$ 4,615,000$ & 0.6 & $\$ 2,845,000$ & 0.4 & $\$ 7,100,000$ & 1.00 \\
\hline & $\begin{array}{l}\text { Componente } \\
\text { Reconversión } \\
\text { Productiva }\end{array}$ & $\$ 4,615,000$ & 0.6 & $\$ 2,845,000$ & 0.4 & $\$ 7,100,00$ & 1.00 \\
\hline 2009 & Sin información & & & & & & \\
\hline \multirow[b]{2}{*}{2010} & Total de programas & $\$ 223,410,48$ & 79.8 & $\$ 74,470,163$ & 26.6 & $\$ 279,880,651$ & 100.0 \\
\hline & $\begin{array}{l}\text { Programa de uso } \\
\text { sustentable } \\
\text { Recursos Naturales } \\
\text { para la producción } \\
\text { primaria }\end{array}$ & $\$ 18,050,00$ & 6.4 & $\$ 5,350,000$ & 1.9 & $\$ 21,400,000$ & 7.6 \\
\hline \multirow{3}{*}{2011} & Total de programas & $\$ 214,000,000$ & 75.0 & $\$ 71,333,333$ & 24.9 & $\$ 285,333,333$ & 100.0 \\
\hline & $\begin{array}{lr}\text { Programa } & \text { de } \\
\text { Sustentabilidad de } \\
\text { los } \quad \text { Recursos } \\
\text { Naturales }\end{array}$ & $\$ 17,725,000$ & 6.2 & $\$ 5,758,333$ & 2.1 & $\$ 23,033,333$ & 8.0 \\
\hline & $\begin{array}{l}\text { Componente } \\
\text { Reconversión } \\
\text { Productiva }\end{array}$ & $\$ 3,100,000$ & 1.0 & $\$ 1,033,333$ & 1.0 & $\$ 4,133,333$ & 1.4 \\
\hline \multirow[b]{2}{*}{2012} & Total de programas & $\$ 98,600,000$ & 74.9 & $\$ 32,866,667$ & 25.0 & $\$ 131,466,667$ & 100.0 \\
\hline & $\begin{array}{lr}\text { Programa } & \text { de } \\
\text { Sustentabilidad de } \\
\text { los } \quad \text { Recursos } \\
\text { Naturales }\end{array}$ & $\$ 13,650,000$ & 10.3 & $\$ 4,450,00$ & 3.3 & $\$ 18,200,000$ & 13.8 \\
\hline \multirow[b]{2}{*}{2013} & Total de programas & $\$ 213,900,000$ & 85.9 & $\$ 35,000,000$ & 14.0 & $\$ 248,900,000$ & 100.0 \\
\hline & $\begin{array}{lr}\text { Programa } & \text { de } \\
\text { Sustentabilidad de } \\
\text { los } \quad \text { Recursos } \\
\text { Naturales }\end{array}$ & $\$ 12,000,000$ & 4.8 & $\$ 3,000,000$ & 1.2 & $\$ 15,000,000$ & 6.0 \\
\hline \multirow[b]{2}{*}{2014} & Total de programas & $\$ 264,100,000$ & 87.7 & $\$ 36,9000,000$ & 12.2 & $\$ 301,000,000$ & 100.0 \\
\hline & $\begin{array}{lr}\text { Programa } & \text { de } \\
\text { Conversión y } & \text { Uso } \\
\text { Sustentable } & \text { del } \\
\text { Suelo y } & \text { Agua } \\
\text { (CUOSSA) } & \\
\end{array}$ & $\$ 37,100,000$ & 12.3 & $\$ 2,318,750$ & 0.7 & $\$ 39,418,75$ & 13.0 \\
\hline 2015 & Sin información & & & & & & \\
\hline \multirow{3}{*}{2016} & Total de programas & $\$ 196,500,000$ & 88.6 & $\$ 25,111,683$ & 11.3 & $\$ 221,611,638$ & 100.0 \\
\hline & $\begin{array}{l}\text { Programa de } \\
\text { Concurrencia con las } \\
\text { Entidades } \\
\text { Federativas }\end{array}$ & $\$ 61,300,000$ & 27.6 & $\$ 15,325,000$ & 6.9 & $\$ 76,625,000$ & 34.5 \\
\hline & $\begin{array}{l}\text { Componente } \\
\text { Concurrencia } \\
\text { Materia Agrícola }\end{array}$ & $\$ 33,726,617$ & 15.1 & $\$ 8,431,654$ & 3.8 & $\$ 42,158,271$ & 19.0 \\
\hline
\end{tabular}

Fuente: elaboración propia 
Según la Memoria documental del Componente Reconversión Productiva 2006-2012, para la operación del programa y sus recursos de apoyo se consideró a la delegación de Sagarpa en Nayarit como la instancia ejecutora de los mismos. En tanto que la dispersora de subsidios sería la Agencia de Servicios a la Comercialización y Desarrollo de Mercados Agropecuarios (ASERCA-DGMP), quienes en conjunto participarían de la obtención parcial de un monto de recursos totales para el componente de Reconversión Productiva a nivel nacional en 2012, de $\$ 797$ millones de pesos ejercidos. Importante señalar que inicialmente se habían autorizado sólo $\$ 455$ millones de pesos en el presupuesto federal.

Nuevamente se presenta otro vacío de información pues el documento oficial en cuestión omite y/o no menciona de manera explícita la cantidad de recursos destinados exclusivamente a Nayarit. Aunque dicho vacío u omisión de información no es propio del documento anterior, sino que se extiende a las propias dependencias e instituciones encargadas de la operación del programa y de sus componentes. Lo otro que también se logra apreciar en las tablas 2 y 3 , es un estrechamiento institucional, es decir, al paso de los años los programas y sus componentes se van reduciendo, algunos desaparecen o después están relacionados a otro programa, situación que no permite una estabilidad institucional, ni en el papel, mucho menos en campo.

En lo que respecta a las familias tabacaleras, cuando cuestionadas sobre su conocimiento del CMCT, de los recursos del Programa de Reconversión o de la reconversión de cultivos, lo que existe es una falta de información o desconocimiento del tema. Las declaraciones de las entrevistas realizadas dan cuenta de ello:

Sí lo he escuchado, pero hasta ahorita no he visto nada, seguimos en lo mismo. Tienen años diciéndonos que hay cultivos alternos, que hay recursos, que la reconversión del cultivo de tabaco pero no hemos visto nada, puras promesas y promesas y promesas (Productortabaco1, 2014).

Lo que no tenemos son recursos y eso es lo que se ocupa para otros cultivos, pero con asesoría y con alguien que nos guie, nosotros estamos dispuestos para aprender y lo lograríamos rápido, rápido lo lograríamos. Siento yo que un $100 \%$ no estaríamos preparados, pero siento que con una poquito de información, de algunos cursos y algunas asesorías que nos den a través de mucho joven preparado que hay, yo siento que nos pondríamos al tanto de cualquier cultivo. No creo que haya cultivos diferentes y difíciles para saber trabajar (Productortabaco1, 2014).

Tengo conocimiento de él, pero desafortunadamente el Convenio Marco los gobiernos federales de cada país no lo han cumplido. En el caso de México no se ha cumplido, pues en teoría la meta era erradicar el tabaco, pero en la práctica no se ha hecho nada (Productortabaco2, 2014).

Esta situación parece no tener importancia, pero realmente la tiene, pues para el caso del tabaco se requiere difusión de información, así como conocimiento de los programas y recursos estables en el largo plazo para acompañar su reconversión, que sean exclusivos y que no se mezclen en la grande tómbola presupuestal donde cualquier productor podría salir beneficiado, incluso no siendo tabacalero, como parece sucedió en el caso del maíz y arroz. 
Experiencias en curso en otros países, Brasil, por ejemplo, pueden ser interesantes para reflexionar el estado actual de la RPT en México. Un tema central es el acceso a información, primero para que las familias tengan conocimiento en general sobre los objetivos del CMCT y de la Reconversión de cultivos, y en segundo para conocer qué ofrecen en materia de recursos y acciones dichas estructuras institucionales a través de sus políticas y programas. De acuerdo con Rudnicki y Guerin, a través de un estudio en Dom Feliciano, municipio tabacalero del Sur de Brasil, antes de proponer alternativas de extensión rural y de diversificación de cultivos, es necesario entender las relaciones que existen entre las familias tabacaleras y otros actores, en ese caso, las industrias del tabaco: al momento de "implementar proyectos de extensión es necesario entender la comunidad, los bloqueos de información, las limitaciones económicas, sociales y culturales de los agricultores" (RUDNICKI; GUERIN, 2014, p. 29). ${ }^{19}$

Por otro lado, experiencias de transición agrícola y articulación institucional brasileñas pueden ser útiles también para Nayarit. El trabajo de Thies y Conterato (2017), presentan el caso de estudio de un municipio productor de tabaco al noroeste del estado de Rio Grande del Sur. Frente a las preocupaciones de los territorios del tabaco por encontrar respuestas a la sustitución del cultivo de tabaco, sobre todo a partir de los desdoblamientos del CMCT, los autores presentan que en Porto Vera Cruz, un proceso de transición sociotécnica basado en la construcción de conocimiento y novedades sociales (novidades), les permitió a los agricultores familiares de ese municipio transitar del cultivo de tabaco a la producción y comercialización institucional de alimentos. La creación de la Cooperativa de los Agricultores de Porto Vera Cruz en 2004, y su articulación con el Programa de Adquisición de Alimentos (PAA), constituyó a éste último en una ventana de oportunidad para que las familias productoras de tabaco del municipio, consiguieran mejorar su calidad de vida y reducir la dependencia con las industrias del tabaco, a través de la diversificación para la producción de alimentos a ser comercializados mediante mercados institucionales (THIES; CONTERATO, 2017)..

Las dos experiencias en Brasil son importantes en términos de sus aportes para repensar/replantear un Programa de Reconversión Productiva del Tabaco. Un primer aprendizaje que puede ser rescatado de estos casos se encuentra en las formas de comunicación, de obtención de información y elementos socioeconómicos y culturales que tienen que ser llevados por una intervención gubernamental como la de Reconversión del tabaco. El segundo aprendizaje, se refiere a una estructura institucional de apoyo, como en el caso del PAA en Porto Vera Cruz, que se constituye en una ventana de oportunidad para articular los programas gubernamentales a los proyectos de las familias tabacaleras.

\footnotetext{
19 A decir de estos autores, la asistencia técnica o la creación de un programa técnico ofrecido por organizaciones, es importante cuando existen situaciones en las cuales un productor no sabe en qué época debe sembrar, y a veces si lo hace, puede ser de forma equivocada. La presencia de un técnico en la propiedad es necesaria, porque frente a un contexto que cambia de forma constante, los agricultores siempre tendrán preguntas o cuestionamientos sobre cosas más baratas y/o accesibles para usar, variedades de semillas, plántulas o cosas que la tecnología les esta sugiriendo (RUDNICKI; GUERIN, 2014, p. 34).
} 


\title{
4.3 LAS INTERFACES Y RELACIONES ENTRE LAS FAMILIAS TABACALERAS Y LOS DIVERSOS ACTORES EN LA PRODUCCIÓN DE TABACO EN NAYARIT
}

\begin{abstract}
El apartado anterior permitió conocer la compleja actualidad del Programa de RPT en Nayarit. En éste se identifica y analiza las posiciones de los diversos actores que participan de la producción de dicho cultivo. Después de mucho anunciarse en Nayarit una bastedad de programas y recursos gubernamentales de apoyo, fuera de algunos insumos y servicios entregados, el grueso de millones de pesos no ha llegado para sostener la transición de aquellas propiedades que se creyeron en la promesa de dicha intervención gubernamental, por lo que, si hoy no están abandonadas a su suerte, tienen problemas de comercialización o de otro tipo.

Una de las declaraciones más fuertes en torno al tema de los recursos económicos de apoyo derivados del Programa de Reconversión Productiva del Tabaco, se dio desde la Asociación Rural de Interes Colectivo (ARIC) de los productores de tabaco. Ésta, es la única organización en Nayarit que agrupa a las aproximadamente tres mil familias productoras de tabaco. El líder de la Aric, entrevistado en 2014 la describe así:
\end{abstract}

Nuestra función es ser interlocutores entre los productores y las empresas tabacaleras. Nuestro trabajo es establecer las condiciones de trabajo y de precio, así como toda la problemática que se presenta durante el ciclo productivo como, por ejemplo, siniestros climáticos, el manejo productivo del cultivo y todo lo que sea parte del proceso. También, hay una relación de nuestra organización apoyando a los agricultores ante el tema de la seguridad social, porque todos los productores tienen seguridad social para ellos y sus familias, a diferencia de otros cultivos, nada más el tabaco y la caña de azúcar de acuerdo con la legislación mexicana pueden tener esos beneficios para ellos y sus familias (Líder tabacalero, 2014).

En 2015, el líder de la ARIC, se expresó contrariamente frente a las declaraciones del subdelegado de Sagarpa, manifestando que sus representados hasta ese momento no habían recibido apoyos para substituir el cultivo de tabaco (AGUIRRE, 2015). Para el dirigente tabacalero, el gobierno federal a pesar de sus buenos deseos, nunca puso en marcha políticas públicas de reconversión que les dieran a los productores la posibilidad de mejorar no sólo sus ganancias, sino también sus condiciones de vida frente a un escenario de crisis e incertidumbres en el que se le ha convertido al campo mexicano. Sin embargo, el mismo líder de la ARIC cuando fue entrevistado en 2014 manifestó una serie de gestiones para la obtención de apoyos;

Nuestra organización (ARIC) ha gestionado recursos desde 2004, desde que se inició el Convenio Marco que fue en el 2003. Hemos estado haciendo gestiones año con año, tanto que ahorita tenemos una solicitud por 20 millones de pesos para apoyo a unos paquetes tecnológicos y por otro lado para nivelación de tierras. Han estado llegando recursos para diferentes rubros y de diferentes partidas presupuestales, pero no de la Reconversión. Desde un principio logramos recursos para materiales, para mejorar el curado del tabaco. En el 2006 se nos apoyó para mejorar el cultivo, pero posteriormente han 
sido apoyos para tecnificación del riego, el drenaje parcelario. Entonces desde el año 2004 a la fecha hemos estado recibiendo recursos del gobierno federal (Líder tabacalero, 2014).

Esta serie de declaraciones, aparentemente contradictorias, han venido tejiendo un entramado verbal bastante confuso, que parece indicar viene construyéndose como parte de una estrategia de biopolítica y/o de intervencionismo para robustecer la capacidad de control y determinista de algunas de las instituciones del Estado mexicano para con los productores de tabaco. Si bien por parte de la esfera oficial se enuncian montos y cantidades de apoyo que forman parte de los compromisos del CMCT en torno de los artículos No. 17 y No. 18, cuando en el peor de los casos no se ha podido acceder como coloquialmente se dice "a un solo peso", los productores tabacaleros han tenido que conformarse con recursos que apenas alcanzan para acciones que se pudieran considerar preparatorias para una transición de cultivos, pero que para ellos no sirven de mucho. Las diversas contradicciones entre productores, líderes campesinos y actores gubernamentales se presentan en la Figura 1.

Figura 1 - Las versiones y contradicciones de la Reconversión del tabaco en la voz de sus diferentes actores

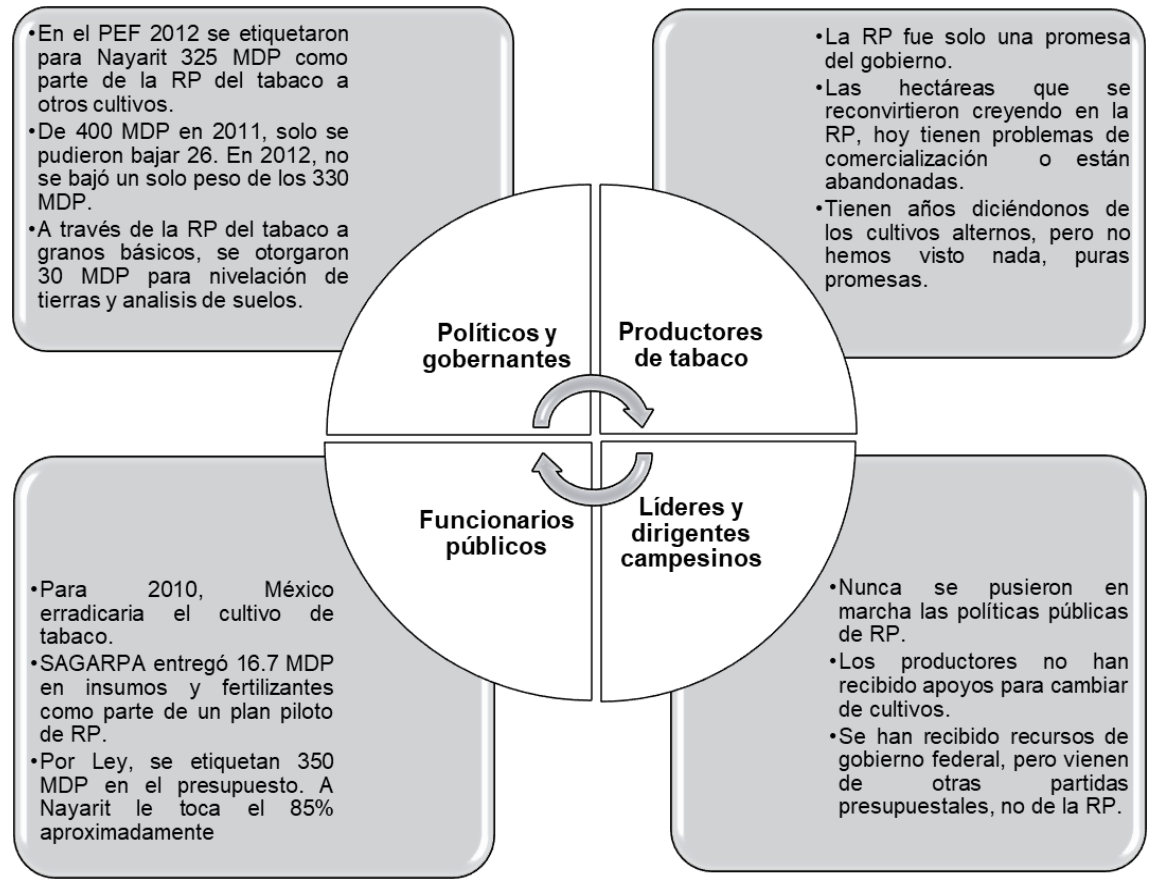

Nota: R.P. se refiere a la Reconversión Productiva; MDP, millones de pesos; PEF, Presupuesto de Egresos de la Federación.

Fuente: elaboración propia a partir de revisión hemerográfica. 
Además de las versiones y contradicciones anteriores, existen otras al interior de la propia ARIC y de las familias tabacaleras. Según el dirigente de la ARIC, con algunos de los primeros recursos de apoyo recibidos "la organización compró y se hizo una central de maquinaria para nivelar tierras a un costo muy bajo del que ofrece cualquier empresa que se dedica a ofrecer este servicio" (Líder tabaquero, 2014). Sin embargo, durante algunas entrevistas, miembros de familias productoras expresaron lo contrario.

la ARIC no nos apoya con lo que se ve en el campo y él [dirigente] sabe bien, porque también es productor, que no nos alcanza el dinero para los trabajos. Él no busca la forma de apoyarnos. Por ejemplo, para empezar a trabajar la tierra para el tabaco, ARIC cuenta con tractores que puede mandar a las comunidades a que realicen trabajos más económicos, que con los propios tractores que hay en las comunidades. Si por ejemplo con los tractores que hay en la comunidad los dueños cobran la rastreada a $\$ 400-500$ pesos la hectárea o la arada, la ARIC tiene sus tractores y puede mandarlos para que la rastreada se cobre a $\$ 300-350$. Es un poquito de ahorro, pero pues ni eso. Los funcionarios que integran la ARIC no gestionan nada de eso para el productor, ni gestionan precios buenos en el recibo del tabaco cuando ya está entregándose. Ellos trabajan de acuerdo con el gobierno. El gobierno y las empresas los tiene controlados (Productortabaco3, 2014).

De la misma manera, las declaraciones de un actor político local coincidían con lo expresado anteriormente, al sostener que las familias no se benefician directamente de los recursos o equipos adquiridos, porque “...pasó que se compró una central de maquinaria para nivelación de tierras que es usada como de manera particular por el dirigente de la ARIC, entonces ellos se dedican a trabajar la tierra pero en otro contexto diferente al de una política pública, no en beneficio de las familias" (Actorpolítico1, 2014).

Las instituciones del Estado involucradas en la Reconversión del tabaco, tanto SAGARPA como INIFAP, en teoría parecen tener claridad en las funciones y propósitos que desde sus campos de actuación cada una debiera realizar. No obstante, tal como señala el trabajo de Hevia (2011), la dificultad mayor para articular estas instituciones y los agentes del Estado no está en el diseño, sino durante la implementación de la política, sus programas y proyectos. En ese sentido, las interfaces entre el Estado, actores gubernamentales y familias tabacaleras, no se han materializado en acciones concretas, a pesar de existir acercamiento entre ellos, como lo señala el líder de la Aric:

¿Existe alguna coordinación entre la Aric, gobierno del
estado, empresas del tabaco, institutos de investigación
y/o universidades para trabajar en buscar alternativas de
cultivos a los productores?
No, pero si hay buena coordinación entre la Aric con el
gobierno estatal y gobierno federal. Nosotros hemos solicitado
que no solamente queremos recursos para que se apliquen a
un paquete tecnológico, sino que también queremos recursos
para construir infraestructura, que haya capacitación, que haya
una investigación de mercados, porque es lo que hace falta.
Sin embargo, es lo que se ha logrado hasta la fecha, pero
nuestra petición es esa. Nosotros queremos sembrar otros 
cultivos, pero también queremos tener a quien venderle, poder darle valor agregado, que haya financiamiento. Entonces, en esa perspectiva es que estamos trabajando en coordinación con los diferentes niveles de gobierno.

Así, al desmenuzar la operación in situ de la Reconversión del tabaco, en lo referente a las organizaciones que deberían estar participando y relacionándose en torno a dicho proceso, no ha quedado claro en la realidad tabacalera nayarita cuál es el alcance de actuación de cada una de ellas, lo que en ocasiones crea confusiones y conflictos en el entendimiento de las funciones que cada una realiza y su relación para con las otras, sobre todo cuando se trata de obtener información de los recursos de apoyo manejados entre ellas.

Si bien el gobierno federal comisionó a Sagarpa la responsabilidad de operar el Programa de Reconversión Productiva y adaptar éste al cultivo de tabaco, el Inifap fue el encargado, a través de una relación horizontal con dicha dependencia, de asesorarla en el establecimiento de cultivos substitutos del tabaco y a su vez el mismo centro de investigaciones, habría llegado a fungir como el puente de entendimiento entre Sagarpa federal y su delegación estatal. Aunque, ya durante la supuesta implementación de su Estudio de Potencial Productivo parece que Inifap no se hizo presente, pues debía haber asesorado a Sagarpa en Nayarit, así como a la Aric de productores de tabaco, aunque todo indica que no lo hizo. 
Tabla 4 - Organizaciones involucradas en torno del Programa de Reconversión Productiva del tabaco en Nayarit

\begin{tabular}{|c|c|c|c|c|}
\hline Institución & $\begin{array}{l}\text { Tipo de } \\
\text { organismo }\end{array}$ & Nivel & $\begin{array}{c}\text { Relación con la } \\
\text { Reconversión Productiva } \\
\text { del tabaco (RPT) }\end{array}$ & Página web \\
\hline $\begin{array}{l}\text { Organización } \\
\text { Mundial de la } \\
\text { Salud (OMS) }\end{array}$ & Multilateral & Internacional & $\begin{array}{l}\text { Principal promotora del } \\
\text { CMCT. Responsable de } \\
\text { vigilar los avances en } \\
\text { materia de cumplimiento a } \\
\text { los compromisos y acciones } \\
\text { asumidos en torno del } \\
\text { CMCT }\end{array}$ & $\begin{array}{c}\text { http://www.who.int/ } \\
\text { es/ }\end{array}$ \\
\hline $\begin{array}{l}\text { Secretaría de } \\
\text { Agricultura, } \\
\text { Ganadería, } \\
\text { Desarrollo } \\
\text { Rural, Pesca y } \\
\text { Alimentación } \\
\text { (SAGARPA) } \\
\end{array}$ & Gubernamental & Federal & $\begin{array}{l}\text { Responsable en } \\
\text { diferentes etapas de la } \\
\text { Reconversión Productiva } \\
\text { del tabaco relación al } \\
\text { cumplimiento de los } \\
\text { compromisos y acciones de } \\
\text { los artículos No. } 17 \text { y No. } 18\end{array}$ & $\begin{array}{c}\text { https://www.gob.m } \\
\text { x/sagarpa }\end{array}$ \\
\hline $\begin{array}{c}\text { Secretaría de } \\
\text { Desarrollo Rural } \\
\text { y Medio } \\
\text { Ambiente } \\
\text { (SEDERMA) }\end{array}$ & Gubernamental & Estatal & $\begin{array}{l}\text { Responsable local de la } \\
\text { Reconversión Productiva } \\
\text { del tabaco a otros cultivos, } \\
\text { valiéndose para ello de la } \\
\text { estructura de las } \\
\text { instituciones } \\
\text { gubernamentales y del } \\
\text { permanente contacto con } \\
\text { las organizaciones de } \\
\text { productores y las familias } \\
\text { tabacaleras. }\end{array}$ & $\begin{array}{c}\text { http://www.sederm } \\
\text { a.gob.mx }\end{array}$ \\
\hline $\begin{array}{c}\text { Instituto } \\
\text { Nacional de } \\
\text { Investigaciones } \\
\text { Forestales, } \\
\text { Agrícolas y } \\
\text { Pecuarias } \\
\text { (INIFAP) } \\
\end{array}$ & Descentralizado & Federal & $\begin{array}{l}\text { Responsable de proponer al } \\
\text { gobierno, estudios en } \\
\text { recomendaciones, en } \\
\text { relación a las actividades y } \\
\text { cultivos con mayor potencial } \\
\text { productivo para substituir al } \\
\text { tabaco. }\end{array}$ & $\begin{array}{c}\text { http://www.inifap.g } \\
\text { ob.mx/SitePages/l } \\
\text { nicio.aspx }\end{array}$ \\
\hline $\begin{array}{c}\text { Asociación } \\
\text { Rural de Interés } \\
\text { Colectivo } \\
\text { (ARIC) }\end{array}$ & $\begin{array}{l}\text { Representación } \\
\text { campesina }\end{array}$ & Estatal & $\begin{array}{l}\text { Trabajar organizativa y } \\
\text { operativamente a nivel local } \\
\text { en la implementación de } \\
\text { actividades y recursos, a } \\
\text { través de su vinculación } \\
\text { entre productores de } \\
\text { tabaco, empresas y } \\
\text { gobierno. }\end{array}$ & No tiene \\
\hline
\end{tabular}

Fuente: elaboración propia

En la realidad diaria de las diferentes comunidades productoras de tabaco en Nayarit parece observarse la naturaleza dual de las organizaciones gubernamentales. Pues si bien tanto Sagarpa y Sederma tienen claridad al respecto de sus objetivos y funciones; ya en campo, terminan por ser presas del contexto adverso que con complicidad estas mismas y los agentes que las representan, han ayudado a construir para extender en el tiempo y espacio las estrategias y lógicas de dominación para con sus "clientes" campesinos, en el intento de preservar la dominación y subordinación de dicho sector.

De esa forma, hasta hoy el Programa de Reconversión Productiva del tabaco no ha funcionado y ha terminado por convertirse en una intervención más del gobierno. Su complejidad, constante transformación no solo en nombres de programas y componentes, sino también en montos de apoyos y organizaciones 
participantes, dan cuenta de la falta de resultados que permitan hablar ya no de un éxito, sino al menos de avances reales y concretos, palpables en la Reconversión del tabaco por granos básicos $u$ otros cultivos en beneficio de las familias productoras de Nayarit.

\section{CONSIDERACIONES FINALES}

Las visiones y contradicciones en torno del Programa de Reconversión Productiva del tabaco son bastantes. La situación actual de esta nueva intervención gubernamental es que al día de hoy no se han cumplido los objetivos y metas que se trazaron inicialmente, sobre todo aquellas relacionadas de manera directa con los artículos No. 17 y No. 18 del CMCT, porque los recursos de apoyo necesarios para la transición productiva del tabaco a otros cultivos están permeados por la pasividad y el control político del Estado mexicano. Contrariamente, han convertido a la Reconversión del tabaco un proceso que carece de una planeación centrada en las necesidades de las familias tabacaleras y que no ha presentado avances ni resultados a través de la presencia de nuevos cultivos que diversifiquen y por ende disminuyan la superficie cultivada con tabaco.

Las interfaces en el contexto tabacalero en Nayarit están plagadas de visiones diferentes y contradicciones entre sus actores. Por un lado, los agentes e Instituciones de Estado hablan de recursos entregados y de haber cumplido compromisos en términos de política pública mediante la entrega de recursos. Sin embargo, en la otra orilla, las familias tabacaleras y sus líderes señalan totalmente lo contrario al referirse que después de más de diez años de la ratificación del CMCT siguen esperando recursos de la tan publicitada Reconversión del tabaco.

Con este ejercicio de etnografía institucional del Programa de Reconversión Productiva del tabaco, parece quedar de manifiesto que en Nayarit no ha existido voluntad o capacidad institucional para acceder a los recursos de apoyos. En el peor de los casos no se ha accedido coloquialmente como se dice a "un solo peso", teniendo las familias tabacaleras que conformarse con apoyos que apenas alcanzan para la entrega de insumos y fertilizantes, nivelación de tierras o análisis de suelos, pero que no son suficientes para un verdadero proceso de cambio del tabaco hacía otro tipo de cultivo. Esa transición, debería al menos envolver difusión de información, investigación, desarrollo de tecnologías locales, acompañamiento en procesos técnico agronómico pero también organizativos, inversiones, fondos de garantía y creación de mercados institucionales, esto para hablar mínimamente de una verdadera política agrícola sin fines de control social y que rompa los tradicionales esquemas de intervención gubernamental. Una verdadera Reconversión del tabaco, podría repensarse/rediseñarse, teniendo como ejemplo el caso de Brasil.

\section{REFERENCIAS}

AGUIRRE, G. La farsa de los apoyos al campo. Tabaqueros no cambiaran de cultivo. Disponible en: http://www.nnc.mx/portada/1403011523.php. Acceso en: 01 abr. 2015.

CAYEROS, L. Las familias del tabaco. Trabajo agrícola familiar y calificación en la producción de tabaco en Jala, Nayarit, ciclos 1998-2006. 2007. Dissertação (Doutorado em Ciências Sociais), El Colegio de Michoacán. Zamora, 2007. 
CEBALLOS, J. Mejoran las condiciones de los tabaqueros en Nayarit: ARIC. Disponible en: http://diariogenteypoder.com/nota.php?id=1415. Acceso en: $01 \mathrm{abr}$. 2015.

DE DIOS, D. Reconversión productiva y nuevas generaciones de familias tabacaleras en el municipio de Santiago Ixcuintla, Nayarit. 2014. Dissertação (Mestrado em Desenvolvimento Econômico Local), Programa de Pós-Graduação em Desenvolvimento Econômico Local, Universidad Autónoma de Nayarit. Tepic, 2014.

DURÁN, L. Abandonan los cultivos de tabaco. Disponible en: http://www.reforma.com/aplicacioneslibre/articulo/default.aspx?id=118651\&md5=225 608c266c61958a5daf9466a14a26f\&ta=0dfdbac11765226904c16cb9ad1b2efe. Acceso en: 01 abr. 2015.

FLETES, H.; RANGEL, F.; OLIVA, A. V.; OCAMPO, G.G. Pequeños productores, reestructuración y expansión de la palma africana en Chiapas. Región y Sociedad, n.57, p.203-239, 2013.

GÁMEZ, C. J.; LAMY, P; BLANCO, A. La implementación del Convenio Marco de la OMS para el Control del Tabaco en México: lecciones aprendidas. En: REYNALES L.; THRASHER, J.; LAZCANO, E; HERNÁNDEZ, M. (Editores), Política pública para el control del tabaco en México. México: Instituto Nacional de Salud Pública. 2013.

GÓMEZ, C. Nayarit sigue siendo líder de producción de tabaco en México. Disponible en: http://www.inforural.com.mx/nayarit-sigue-siendo-lider-de-produccionde-tabaco-en-mexico/. Acceso en: 02 nov. 2018.

HEVIA, F. La difícil articulación entre políticas universales y programas focalizados Etnografía institucional del programa Bolsa Familia de Brasil. Gestión y Política Pública, v. XX, n.2, p.331-379, 2011.

LEÓN, A. Aumentará en Nayarit la producción de arroz: SAGARPA. Disponible en: $\quad$ https://www.inforural.com.mx/aumentara-en-nayarit-la-produccion-de-arrozsagarpa/. Acceso en: 02 nov. 2018.

LUGO, U. Cultivos de tabaco y caña de azúcar cambiarán por maíz amarillo. Disponible en: http://nayaritenlinea.mx/2014/01/24/cultivos-de-tabaco-y-cana-deazucar-cambiaran-por-maiz-amarillo/. Acceso en: 02 nov. 2018.

MADERA, J. Estrategias de sobrevivencia y economía campesina ante el neoliberalismo: el trabajo familiar en la producción de tabaco en Nayarit, 19902000. 2000. Dissertação (Mestrado em Desenvolvimento Regional), El COLEF. Tijuana, 2000.

MADERA, J.; DE DIOS, D. (Re)Configuración de saberes y reconversión productiva del tabaco en la costa norte de Nayarit. In: GARRAFA, O. et al. (coords.) México rural ante los retos del siglo XXI. Tomo IV: Políticas públicas y territorialidades, México: AMER/UAN/UACh/UAM, 2017. 
MÉNDEZ, E. Crisis agobia a los tabacaleros por contrabando y piratería. Disponible en: https://www.excelsior.com.mx/nacional/2013/11/19/929388. Acceso en: 02 nov. 2018.

MENGEL, A. Tratados internacionais e disputas locais: A Convenção Quadro para o Controle do Tabaco e as disputas entre os atores da cadeia produtiva no Brasil. 2011. Dissertação (Mestrado em Desenvolvimento, Agricultura e Sociedade), Programa de Pós-Graduação de Ciências Sociais em Desenvolvimento, Agricultura e Sociedade, Instituto de Ciências Humanas e Sociais, UFRRJ, Rio de Janeiro, 2011.

MÉXICO. Diario Oficial de la Federación - DOF. 2005. Convenio Marco de la Organización Mundial de la Salud para el Control del Tabaco. Acessado em: 01/07/16.

http://www.cedhchihuahua.org.mx/portal/tratados/pdf/133.pdf. Acceso en: 01 jul. 2016.

NOTIMEX. La ley antitabaco dañará a Nayarit. Disponible en: http://www.cnnexpansion.com/economia/2008/02/24/la-ley-antitabaco-danara-anayarit._Acceso en: 04 nov. 2018.

ORGANIZACAÇÃO MUNDIAL DA SAÚDE - OMS. Alternativas económicamente viables al cultivo de tabaco (en relación con los artículos 17 y 18 del Convenio Marco de la OMS para el Control del Tabaco). Conferencia de las Partes en el Convenio Marco de la OMS para el Control del Tabaco. Sexta Reunião, Moscou, Rússia, 13-18 de outubro de 2014.

PÉREZ, M. Debacle de productores de tabaco en Nayarit, Veracruz, Chiapas y Jalisco. Disponible en: http://www.taringa.net/comunidades/mesif/1514937/Debacle+de+productores+de+ta baco+en+Nayarit\%252C+Veracruz\%252C+Chiap.html. Acceso en: 04 nov. 2018.

REGALADO, J.; RODRÍGUEZ, C. La función de la Oficina Nacional para el Control del Tabaco en México. Salud Pública de México, v. 50, n. 3, p. S355-S365, 2008.

RUDNICKI, C. S.; GUERIN, Y. S. As mediações na trajetória de vida dos agricultores do tabaco no Rio Grande do Sul. Extensão Rural, Santa Maria, v. 20, n. 1, p. 27-36, jan./mar. $2014 . \quad$ Disponible en: https://periodicos.ufsm.br/extensaorural/article/view/7518/pdf Acceso en: 04 nov. 2018.

SAGARPA. Servicio de Información Agrícola y Pecuaria (SIAP). México. 2019.

SAGARPA. Servicio de Información Agrícola y Pecuaria (SIAP). México. 2012.

SAGARPA. Memoria documental del Componente Reconversión Productiva 2006-2012. SAGARPA, 2012. Disponible en: https://sagarpa.gob.mx/Transparencia/PNRCTCC/PNRCTCC\%202012/Memoria\%20 Documental\%20Componente\%20Reconversion\%20Productiva\%20\%2030102012.pd f. Acceso en: 02 nov. 2018. 
SAGARPA. Reconversión del cultivo de tabaco en México. México, 2008.

SAGARPA. Reconversión productiva sustentable. SAGARPA, 2004. Disponible en:

https://slideplayer.es/slide/3568224/?fbclid=IwAR0kSSQ89OezxTR7EiSv53VHjrQJaq fZMIOhtkbGzkz_Cl2eeQupegfANgl (Taller: Reconversión productiva y agricultura por contrato). Acceso en: 02 nov. 2018.

THIES, V. F.: CONTERATO, M. A. Da produção de tabaco ao cultivo de alimentos: novidades e transições sociotécnicas na agricultura familiar de Porto Vera Cruz - RS. Extensão Rural, Santa Maria, v. 24, n. 1, p. 62-78, maio 2017. Disponible en: https://periodicos.ufsm.br/extensaorural/article/view/23658/pdf. Acceso en: 02 nov. 2018.

TORRES, O. F.; HERRERA, F.T.; VIZCARRA, I.B; LUTZ, B.H.B. Etnografía institucional del proyecto estratégico de seguridad alimentaria (PESA) en una comunidad mazahua. Nueva Antropología, v.28, n.82, p.51-81, 2015.

VIZCARRA, I.; FARFÁN, F. El programa "Vete sano y regresa sano": lecciones de una etnografía institucional en el Estado de México. Ruris, v.6, n.2, p.123-154, 2012. 